\title{
Foucault y las prisiones en movimiento: sobre el enclaustramiento en los buses de Lima
}

\section{Foucault and moving prisons: about the confinement in the buses of Lima}

\author{
Christopher Rojas Quispe \\ Universidad de Lima
}

\section{RESUMEN}

El objetivo de este artículo es mostrar aquello que discurre en el corazón del día a día: la unidad de transporte, los usuarios y los personajes; lo cual, no obstante, es "pasado por alto". El soporte epistémico está constituido por los conceptos de Foucault extrapolados al universo siempre movible del transporte, la ciudad y la identidad limeña. Para tal efecto, se definen conceptos tales como ciudad, bus, pasajero y prisión, y se lleva a cabo una breve tipología que refleja y pone en acción la dinámica de estos y sus respectivas redefiniciones "sobre la marcha".

Palabras clave:

ciudad, bus, pasajero, prisión

\section{ABSTRACT}

The objective of this article is to show what happens at the heart of daily life in Lima — buses, passengers and characters-, a situation which is ignored. The epistemic basis consists of the concepts of Foucault extrapolated to the moving universe of transportation, the city of Lima and its peoples' identity. For this purpose, concepts such as "city", "bus", "passenger" and "prison" are defined. Moreover, a brief typology that reflects and sets in motion their dynamics and redefinitions is developed "on the fly".

Keywords:

city, bus, passenger, prison. 


\section{Lima: transporte y transeúntes}

$\mathrm{E}^{*}$ Perú ya se prepara para celebrar el bicentenario de nuestra independencia en el 2021. El transporte público, tema aún irresuelto, forma parte de la agenda nacional y, como tal, merece consideración especial; además, se tiende a circunscribir su problemática a la infraestructura, soslayando así todo lo que surge antes, durante y después de él. Por tanto, echemos un vistazo a la realidad del transporte público en Lima y Callao desde el corazón mismo, es decir, el bus.

El transporte en Lima se erige como uno de los temas cumbre de nuestra cultura. El sistema informal imperante data de la década de los sesenta ${ }^{1}$ y responde, como manifestación sociológica, por un lado, de manera connatural a la ausencia de un plan por parte de los gobiernos de turno para hacer frente a la ola migratoria ${ }^{2}$ de aquel entonces $y$, por otro, al devenir inevitable de lo urbano como categoría itinerante.

En efecto, lo urbano es difuso, mutable por naturaleza, poroso, nunca constante (Joseph, 1988). A su vez, es circunscrito a todo aquello opuesto a cualquier claridad estructural, merced a su carácter veleidoso, oscilante, casual, espontáneo (Delgado, 1999). Por su parte, el discurso oficial se arroga el derecho de sistematizar la ciudad, de proveerla de sentido, de poner orden al supuesto desconcierto connatural al propio devenir citadino, toda vez que la manera como se configura una ciudad responde, sobre todo, a la propia dinámica de su gente, esto es, sus agentes de cambio y el espacio cambiante. De ahí que cobre total sentido una topografía de poder, presta a aplicar una taxonomía sobre una ciudad sin órganos, escurridiza y que, pese a los denodados esfuerzos de una urbanística y paisajística moderna extrema, falla al querer emular contextos propiamente naturales, como si de una obra arquitectónica se tratase.
En ese orden de reflexión, podríamos aventurarnos a decir que, más que signos o significados, la ciudad se encuentra configurada a partir de significantes móviles, que las cartografías generales fracasan al querer retratar. Pensemos más en la urbe como una gran sábana de espacio abierto, definida y redefinida a partir de las coreografías dibujadas por los transeúntes, resignificada y resignificante "al paso", al antojo de los que por ahí transitan; o como una masa elástica multiforme y colorida, supeditada más al ímpetu caprichoso de la propia dinámica socializante que a algo estable. $Y$, por eso mismo, la ciudad se encuentra cubierta de señalizaciones, rutas oficiales, una red de semáforos, cableado, asfalto, estacionamientos, túneles, puentes, peajes y demás, que exhalan control y mesura en el que la transita. Frente a ello, tanto el transeúnte como los medios de transporte deben hacer frente ("dar la cara"), ignorar ("dar la espalda"); en suma: combatir, negociar, otorgar concesiones o sucumbir.

Cabe resaltar, por eso, la noción de ciudad como texto, pues debe ser leída en tanto poseedora de un carácter textual, y susceptible de ser interpretada a cada paso, en el día a día (Mangieri, 2006). Lectura que estalla en los ojos del transeúnte y trae por los suelos las ya cansinas definiciones tradicionales de texto ligadas al lenguaje escrito.

Ahora bien, al subir a cualquier unidad de transporte de la capital, constatamos cuan parecida es esta a la ciudad, a la calle, a la esquina; saber mínimo necesario requerido para darse cuenta de las dinámicas en curso en la continuación de su ruta: vendedores, cómicos, delincuentes, música, ruido, códigos, lenguaje, informalidad, cultura y tradiciones discurren de la calle al bus y del bus a la calle, dentro y fuera de él. Adentro el sujeto es y deviene, haciéndole frente a la jungla de cemento de la que nos habla el poeta ${ }^{3}$ : la también llamada jungla de concreto. $Y$ empleamos el verbo

1 Durante las décadas de los sesenta, setenta y ochenta, y debido al centralismo cada vez más protagónico de Lima, traducido en una ola migratoria, conjugada con una incapacidad del gobierno para hacer frente a la situación, la exacerbación y el paulatino colapso del parque automotor se hizo evidente, así como el calvario experimentado por los usuarios. Y en los noventa, la ausencia de un marco legal necesario y la ligereza del gobierno de turno al dar carta libre a los propietarios de las llamadas combis, merced a la creciente demanda de transporte, potenció el efecto multiplicador iniciado décadas anteriores.

2 Según los Censos Nacionales de Población del INEI, entre 1972 y 1993, la cantidad de migrantes que tuvieron como destino Lima pasó de un 43,5 \% a 39,5 \%. Destacan dos grupos, los que aportan un mayor volumen de migrantes: Áncash (10,4 \%), Junín $(10,1 \%)$, resto del Departamento de Lima y Callao (9,5 \%) y Ayacucho (8,9\%), y los que aportan menos: Cajamarca (5,9 \%), La Libertad (5,7 \%), Piura (5,4 \%), Apurímac (5,3\%), Ica (4,7\%), Arequipa (4,5\%), Cusco (4,5\%) y Huancavelica (4,2 \%), entre otros.

3 Hector Lavoe (Puerto Rico, 1946-1993), Ilamado también "el cantante de los cantantes", fue un vocalista de salsa conocido, idolatrado y recordado por sus letras con contenido social, cercanas a la realidad del "de a pie", del lumpen, del preso, del marginal. Destaca, entre ellas, una frase, casi una sentencia: "la calle es una selva de cemento". A su vez, Bob Marley (Jamaica, 1945-1981) destaca por su música y su compromiso con la sociedad. Concrete jungle, jungla de concreto en español, canción de su primer álbum, se refiere precisamente a lo difícil de la vida cotidiana, a los peligros de la calle. 
devenir, pues, desde sus atalayas, los pasajeros pueden observar lo circundante, lo que está siendo allende las ventanas, para luego volver a su estado momentáneo de contemplación, de pasajero, muy parecido a las pinturas del norteamericano Edward Hopper ${ }^{4}$.

Y es ahí donde la definición de no lugar tiene lugar, esto es, lugar flotante, de intercambios varios, protocolares, carentes de sentido, vacuos, inerciales, tales como los aeropuertos, estaciones de bus, supermercados y, desde luego, medios de transporte (Augé, 1992).

El $70 \%$ de limeños utiliza transporte público (buses, combis, cústeres y corredores complementarios) para desplazarse de un lugar a otro; asimismo, ese público permanece, en promedio, 105 minutos al día a bordo de ellos. Es decir, suman un total de dos años de su vida viajando (Ipsos Perú, 2015).

La primera observación que salta a la vista es el tiempo $\mathrm{e}$, inextricablemente, las condiciones en las que discurre. Saturación física inevitable y, en ese sentido, necesidad imperiosa de crear las barreras del caso necesarias, más allá de las fronteras del cuerpo, de la proxemia ${ }^{5}$. Importancia crucial del levantamiento de divisiones o muros de contención, que contengan el desborde del otro sobre nosotros, o el nuestro sobre ellos, puertas giratorias de entrada y salida, cubículos independientes y compartidos, roles y máscaras dentro del teatro en movimiento del bus.

Las estrategias de supervivencia, de poder, suponen abolir las fronteras físicas del bus y erigir otras nuevas, más acordes con los tiempos actuales, suerte de pequeñas atalayas individuales, panópticos debilitados o diluidos ya no en estereotipos o modelos masivos a pequeña escala, sino en tipos estéreo, individuaciones más que individuos. En ese sentido, se podría decir que tanto el conductor como el cobrador de la unidad de transporte son quienes dominan y someten a sus anchas a los usuarios. No obstante, la idea es ir más allá, tal vez como punto inicial no estaría mal, pero queremos hacer hincapié no en un cuerpo que integre a todos los transeúntes, a manera de un gran cuerpo dócil ${ }^{6}$, léase chofer y cobradores castigadores y audiencia castigados, sino en qué medida cada porción de espacio reterritorializado ${ }^{7}$ responde y corresponde a una posible estrategia del poder y a su respectivo cuerpo dócil. Por eso, proponemos una lectura actualizada y aplicada de Foucault a un fenómeno social contemporáneo.

\section{Foucault y el bus}

En primer lugar, el bus opera como una prisión en movimiento, un enclaustramiento que precisa, por parte del viajero, estrategias de escape, líneas de fuga, tangentes imaginarias. En efecto, la estructura del bus, su configuración, los asientos, el estar de pie sin rozar demasiado a los otros, estar sin estar, supone grados de tensión entre los que ahí se encuentran.

La misma configuración del vehículo provee de ventanas a través de las cuales es posible huir del encierro, aunque en ocasiones ensimismándose, realizando un ejercicio introspectivo, pasando de lo externo a lo interno. De las ventanas más tradicionales y sin efectismos, pasamos paulatinamente a las tecnológicas; en ese sentido, la lectura de diarios, revistas o libros, incluso en nuestro país, se yergue como posibilidad. Le siguen escuchar música y, tal vez la más popular por estos tiempos: la ventana del celular; la cual, a su vez, provee de más ventanas.

Recordemos que la noción de panóptico, trabajada por Jeremy Bentham y posteriormente acogida por Foucault, supone a alguien que, desde su atalaya, desde esa posición superior, controla sin ser visto a los demás: lugar privilegiado para el vigía o controlador. El poder radica precisamente en lograr que los condenados hagan lo que mandamos, pues ignoran si están siendo observados o no; $y$, al mismo tiempo, minimizar toda posible comunicación entre ellos.

4 El célebre pintor norteamericano Edward Hooper (Estados Unidos, 1882-1967) se caracterizó, sobre todo, por pintar escenas cotidianas en diversos contextos. Resalta el carácter introspectivo de sus pinturas, cuyo eje común siempre fue la soledad, la quietud, la incomunicación, la indiferencia y la distancia.

5 Estamos empleando la noción de proxemia tal cual la entiende Edward T. Hall (Estados Unidos, 1914-2009); es decir, la distancia establecida entre las personas al interrelacionarse.

6 Estamos haciendo uso de la categoría foucaultiana denominada cuerpo dócil, tal como es desarrollada en su libro Vigilar y castigar. A saber, la existencia de un cuerpo manipulable y, en esa medida, moldeable de acuerdo a los designios de una estrategia de poder que responda a los fines que, quien la ponga en práctica, juzgue conveniente.

7 Estamos haciendo uso de la noción de territorialización, tal cual la emplea Gilles Deleuze (Francia, 1925-1995) en Mil mesetas. Capitalismo y esquizofrenia. 
Y, en segundo lugar, apostamos por una idea versátil de poder, similar a la de discurso ${ }^{8}$, propuesta por Foucault, no fija, antes bien viva, capaz de asumir roles e intercambiarlos sobre la marcha, independiente de los sujetos. Estos serían estrategas de poder pasajeros, momentáneos, lo que dure su periplo diario, su capricho, cuando no las circunstancias en las que se ven envueltos. $Y$, en esa medida, pensar en instancias que toman o asumen la posta mutuamente, el relevo de poderes o micropoderes, sede cada uno de un poder transitorio e intercambiado a la brevedad por el que ejerce o carece de poder, según sea el caso.

De más está decirlo, aunque el bus informal represente el descontrol y, en esa medida, la ausencia de indicadores que permitan medir o aquilatar lo circundante, aun así existen reglas que se deben seguir, probablemente más flexibles que en el sistema formal ${ }^{9}$, pero precisamente porque no hay un sistema rígido único, surge su correlato, una versión desgastada del primero: asientos desvencijados, espejos rotos y sucios, puerta automática quejumbrosa, tarifas flexibles, música variopinta y estridente, licencia para comer y llevar animales. Se ha pasado de un sistema completamente rígido a uno más dúctil, maleable de acuerdo a las circunstancias; pero, al fin y al cabo, resultado de un control mayor, omnisciente, representado por el sistema de transporte.

Así, los pasajeros deben alinearse a los designios de la norma informal del bus. Podríamos decir que esta es definida recién cuando está en ruta, durante la marcha; de lo contrario pulularía como una suerte de tren fantasma ${ }^{10}$. En otras palabras, se define por las interacciones que se ponen en práctica; esto es, por la acción de los sujetos conjugada con la configuración del espacio, la amalgama que surge del encuentro entre los dos.
Y desde esa perspectiva, podemos elaborar una tipología, al menos transitoria, del poder.

\section{Elvendedor}

Algo que caracteriza al limeño promedio es su capacidad para reinventarse, su habilidad camaleónica para hacer frente a la adversidad. Producto de lo que mencionamos al inicio, buena parte de la informalidad se encuentra encarnada en los vendedores callejeros.

El vendedor sube al bus y delimita así su campo de acción, su accionar, acaba de crear un panóptico a su medida, a fuerza de ser demasiado evidente ha devenido invisible, lo obvio es tal que evita poder ser visto $y$, más bien, en ese sentido, se le pasa por alto. Por su parte, los "prisioneros" —léase pasajeros - evitan mirar al vendedor, pues el mínimo contacto supone un posible sometimiento a él, traducido en una caridad efectiva: la atención como antesala al acto de colaboración. Esquivar la mirada, fingir estar dormido, entre otras, resultan estrategias para hacer frente a esta situación. El objetivo es claro, debilitar al ente supremo de poder a través de una estrategia elaborada "al paso".

Por su parte, los vendedores relatan la historia de su vida, inventada o fidedigna, hay que parecer para ser, de ahí el carácter histriónico explotado por sus personajes, roles y máscaras, harto estudiados por Irving Goffman, a propósito del estigma social' ${ }^{11}$. Así, el espacio del bus deviene el lugar de los microrrelatos y, en esa medida, la sentencia sobre el ocaso de los grandes relatos, vertida en La condición posmoderna por Jean-Françoise Lyotard, se encuentra plenamente vigente ${ }^{12}$. Por eso, Foucault nos recuerda que la historia de las grandes hazañas ha estado vinculada a otra modalidad de poder,

8 Al inicio de su obra El orden del discurso, Foucault manifiesta su deseo de ser introducido por el texto mismo, que este trascienda al sujeto narrador y no que manifieste su carácter omnisciente sobre el discurso. A su vez, en La arqueología del saber, él ya había introducido su definición tan particular de discurso; a saber, algo vivo, nunca fijo, más bien dinámico, que discurre precisamente y que siempre es sujeto de actualización, de ser.

9 Desde el año 2015, se implantó parcialmente un sistema formal de transporte, llamado Corredor azul, en la capital. Caracterizado por la pulcritud, estridencia nula, tarifa fija y rapidez, hoy por hoy representa una revolución en lo que a reforma de transporte se refiere. Cabe resaltar, sin embargo, que su éxito viene de la mano de la desaparición de todas las otras líneas competidoras.

10 La concepción de espacio como forma que en sí misma no produce efecto alguno es introducida por George Simmel en su libro Sociología 2. Estudios sobre las formas de socialización. También lo llama actividad del alma, el modo que tienen los hombres de agrupar, en intuiciones unitarias, los efectos sensoriales que en sí mismos carecen de lazo alguno.

11 Merecen especial mención los estudios del sociólogo norteamericano Irving Goffman sobre la manera en que los marginados hacen frente a sus estigmas, a su condición casi connatural a ellos; vía estrategias de poder también, de cara al yugo perpetrado sobre ellos, y a partir de sus estigmatizadores. Estrategias de poder de "entrada" y"salida" por parte de ambos bandos, los perpetradores y los condenados, como piezas móviles de un mismo rompecabezas.

12 En su libro La condición postmoderna, Jean-Françoise Lyotard hace referencia al viraje histórico del mundo contemporáneo; a saber, que el foco haya pasado de los grandes sucesos y problemas históricos a aquello que de particular tenga algún suceso o acontecimiento. 
mientras que las nuevas técnicas de sometimiento suponen un viraje $y$, también, un acercamiento a la individualidad-génesis ${ }^{13}$.

\section{Eldelincuente}

Si pensáramos con detenimiento en la recomendación de ocultar mejor una hoja en el lugar más adecuado, es decir, en el bosque, tal vez podríamos comprender un poco más con respecto a la importancia del factor sorpresa y de los distractores, al momento de camuflarse.

Nos referimos al delincuente que se oculta entre el gentío, se pierde, se escamotea como un pasajero más. El carterista es tal precisamente porque los demás están obnubilados en sus quehaceres cotidianos, máxime si por estos tiempos nadie tiene tiempo para nada o le dedican tiempo a todo $y$, en esa medida, los sujetos se someten a los designios de la tecnología. Recordemos que el bus es una invitación explícita, sino a la abstracción, por lo menos a perderse de uno mismo, al estar fuera de sí. He ahí precisamente la condición a la cual compele el enclaustramiento del viaje en bus, suerte de válvula de escape de la condición misma del viajero promedio.

De este modo, todos pueden ser pasajeros en la medida que se comporten como tales, viajeros estándar, usted, yo, el de al lado, el de atrás, el de adelante y el que delinque en el bus, vía la modalidad de perderse en el gentío, de hacerse pasar por alguien más, de parecerse a o de minimizar las diferencias entre él y el resto. Simplemente, toma lo característico de los pasajeros, se apropia de lo que ellos comparten, hace suyas sus características y las encarna.

\section{Elvoyeur}

Afrontémoslo, el viraje cultural de fines del siglo xIx, y cuya materia prima encuentra solaz en el siglo $x x$, ha visto el zénit de su apogeo durante el desarrollo galopante de las comunicaciones o, tal vez, debido a estas.

Así, el "ver" se constituye en el "penetrar en el alma del otro", radiografía externa que conduce a una interna; podría hablarse del otro como infierno (Sartre, 2004). Maximizar lo visto, el detalle, inmortalizar el instante vía su propia obsolescencia constante. Nos referimos a lo pornoestéreo, la fruición del plano de detalle, el lentegrano angular de la cámara que facilita recogerlo, asirlo y hacerlo a nuestra medida (Baudrillard, 1998); he ahí la función de lo ocular en estos tiempos.

Se dirá que el encierro mismo potencia el ver, el ver sin ser visto, el ocultamiento para mejorar el ver; ignorar el paisaje representa ir contracorriente de lo que se encuentra en boga en la actualidad; es decir: hallar, circunscribir y registrar lo que acontece ante nuestros ojos, merced a las nuevas tecnologías. Pues solo a través de ellas, a la posterior visualización de lo registrado, recién podemos ver el acto perpetrado. No es gratuito, en ese sentido, la enorme cantidad de videos privados, tanto de contenido sexual como de interés público, que circulan a diario en los medios de comunicación. Es la imperiosa dicotomía necesaria, por un lado, de dejar verse, de mostrarse y, por otra, de ver, de quitar el velo a lo oculto, a lo más recóndito. En ambos casos subyace el siguiente adagio: "a mayor privacidad develada, mayor interés y, por tanto, mayor avidez por obtener más".

En nuestro caso, las posiciones, las distancias y las alturas provistas por el bus, conjugada o no con la tecnología, dan pie al intercambio de miradas, goce visual $y$, de darse el caso, registro selectivo para el posterior disfrute.

Se trata de minimizar los espacios aún más y maximizar el aglutinamiento, aprovecharlo hasta el límite; al elegir una posible víctima, esta deviene un cuerpo dócil, fragmento o parte del todo, hombre o mujer; aunque, valgan verdades, casi siempre son los hombres los perpetradores. La anatomía de ella es reducida a una porción que representa el todo, una zona erógena: el talón, el empeine, las pantorrillas, los glúteos, los muslos, el sexo, el busto. Si se está de pie, el nacimiento del seno y, posiblemente, la ropa interior; si se está sentado, los pliegues de la piel adheridos al vestido, la tetamenta en contrapicado.

\section{El viajero estándar}

De pie o sentado, cómodo o incómodo, masculino o femenino, joven o anciano, dormido o despierto, el viaje en bus constituye una explosión sensorial y cognitiva. Cierto es que la mayor parte de las veces es un suplicio, y que la mayoría preferiría desplazarse en taxi o en carro particular; sin embargo, el viajero promedio se repantiga en el asiento, se deja estrujar, se pierde entre

13 Nos referimos a las nuevas técnicas de sometimiento, tal cual lo expresa Foucault, a propósito del viraje experimentado de una macrofísica a una microfísica del poder, de donde resaltan las particularidades en desmedro de los acontecimientos solemnes o históricamente grandilocuentes. 
el gentío, descubre nuevos límites espaciales. He ahí el grado de conciencia cero, transmutado en algo más que lo meramente físico, entendido como algo diferente a lo inmaterial.

Por un lado, la movilidad del bus supone entrar, sin proponérselo, en aquella dimensión paralela, interna. El viaje en bus, realmente, conlleva a cuotas inerciales, cuando no soporíferas; no obstante, el movimiento externo induce, inconscientemente, a un observar, a un ensimismamiento en la dentrura cotidiana de cada uno, un extraviarse y, por qué no, escaparse y adentrarse en una dimensión distinta, tanto temporal como de lugar. Sensación de no saber si es la ciudad la que se mueve o es el vehículo el que está en movimiento; efecto inercial del cuerpo al viajar, tanto en el desplazamiento, como en la parada.

Volvamos al tema del espacio, fundamental en el quehacer que nos ocupa, y recordemos que las sensaciones de proximidad o distancia espaciales no tienen que ver con la cercanía o lejanía de los involucrados, sino con el eslabonamiento y conexión espirituales o psicológicas, ejercidas a partir de ellos mismos (Simmel, 1986). En efecto, el bus, bien podría estar atiborrado, pero eso no es suficiente ante el dicho "Al fondo hay sitio". Siempre habrá lugar para algunos más y precisamente de eso se trata, de ensanchar las dimensiones terrenales de lo físico; al final, los pasajeros se acostumbran. Si se diera el caso opuesto, pocos pasajeros y alguien desafiante, el efecto se vería sobredimensionado. Por ejemplo, un sujeto de aspecto claramente amenazador, cortes en los brazos y tatuajes en el cuerpo, resulta muchísimo más atemorizante si la unidad de transporte se encuentra a medio llenar o casi vacía; mientras que, de tratarse del mismo espacio pero con más gente, el efecto inquietante probablemente se diluiría.

Vemos, pues, en esta breve tipología o caracterización de personajes el juego de poderes y estrategias, la dinámica del discurso, precisamente como lo entendió Foucault: algo vivo, un sistema que se define por su actualización constante a través del sujeto, que lo determina y redefine a su paso. En suma, el sujeto como lugar del discurso y, a su vez, como hacedor del primero $y$, en esa medida, los relevos necesarios y las distensiones del caso de los sujetos, los estrategas y las estrategias de poder. Y corroboramos, en la práctica, cuán frágiles resultan las categorías positivistas de demarcación, de aplanamiento de lo variopinto, de búsqueda de casuísticas recurrentes, en aras de una uniformidad, sobre todo dentro de un terreno polisémico y cenagoso, como son la urbe y sus transeúntes.

\section{Referencias}

Augé, M. (1992). Los no lugares. Espacios del anonimato. Una antropología de la sobremodernidad. Barcelona: Gedisa.

Baudrillard, J. (2007). De la seducción. Madrid: Cátedra.

Deleuze, G. (2004). Mil mesetas: Capitalismo y esquizofrenia. Valencia: Pre-textos.

Delgado, M. (1999). El animal público. Hacia una antropología de los espacios urbanos. Barcelona: Editorial Anagrama.

Empresa Editora El Comercio. (2007). Lima capital. Estilos de gran urbe. Lima: Autor.

Foucault, M. (1976). La arqueología del saber. México: Siglo Veintiuno Editores.

Foucault, M. (1976). Vigilar y castigar. Nacimiento de la prisión. México: Siglo Veintiuno Editores.

Foucault, M. (1979). Microfísica del poder. Madrid: Las Ediciones de La Piqueta.

Goffman, E. (2012). Estigma: la identidad deteriorada. Buenos Aires: Amorrortu Editores.

Hall, E. (1963). Proxemics: the study of man's spatial relations and boundaries. New York: International University Press.

Joseph, I. (1988). El transeúnte y el espacio urbano. Buenos Aires: Gedisa.

Lyotard, J.-F. (1994). La condición postmoderna. Informe sobre el saber. Madrid: Ediciones Cátedra.

Mangieri, R. (2006). Tres miradas, tres sujetos. Eco, Lotman, Greimas y otros ensayos semióticos. Madrid: Biblioteca nueva.

Sartre, J.-P. (2004). A puerta cerrada. Buenos Aires: Losada.

Simmel, G. (1986). Sociología 2. Estudios sobre las formas de socialización. Madrid: Alianza. 